\title{
AMLODIPINE ACCELERATES BONE HEALING IN A STABLE CLOSED FEMORAL FRACTURE MODEL IN MICE
}

\author{
M.M. Menger ${ }^{1,2, *}$, B. Merscher ${ }^{2}$, C. Scheuer ${ }^{2}$, B.J. Braun ${ }^{1}$, S.C. Herath ${ }^{1}$, M.F. Rollmann ${ }^{1}$, D. Stenger ${ }^{2,3}$, \\ T. Später ${ }^{2}$, T. Pohlemann ${ }^{3}$, M.D. Menger ${ }^{2}$ and T. Histing ${ }^{1}$ \\ ${ }^{1}$ Department of Trauma and Reconstructive Surgery, Eberhard Karls University Tübingen, BG Trauma \\ Center Tübingen, 72076 Tübingen, Germany \\ ${ }^{2}$ Institute for Clinical and Experimental Surgery, Saarland University, 66421 Homburg/Saar, Germany \\ ${ }^{3}$ Department of Trauma, Hand and Reconstructive Surgery, Saarland University, 66421 Homburg/Saar,
} Germany

\begin{abstract}
Calcium channel blockers (CCBs), which are widely used in the treatment of hypertension, have been shown to influence bone metabolism. However, there is little information on whether CCBs also influence the process of fracture healing. Therefore, the effect of the CCB amlodipine on bone healing was studied in a stable closed fracture model in mice using intramedullary screw fixation. Bone healing was investigated by radiology, biomechanics, histomorphometry and Western blot analysis 2 and 5 weeks after fracture healing. Animals were treated daily (post operatively) per os using a gavage with amlodipine low dose (1 mg/ $\mathrm{kg}$ body weight, $n=20)$, amlodipine high dose $(3 \mathrm{mg} / \mathrm{kg}$ body weight, $n=20)$ or vehicle $(\mathrm{NaCl})$ (control, $n=20$ ) serving as a negative control. At 2 and 5 weeks, histomorphometric analysis revealed a significantly larger amount of bone tissue within the callus of amlodipine low-dose- and high-dose-treated animals when compared to controls. This was associated with a smaller amount of cartilaginous and fibrous tissue, indicating an acceleration of fracture healing. Biomechanics showed a slightly, but not significantly, higher bending stiffness in amlodipine low-dose- and high-dose-treated animals. Western blot analysis revealed a significantly increased expression of bone morphogenetic protein (BMP)-2 and vascular endothelial growth factor (VEGF). Moreover, the analysis showed a 5-fold higher expression of osteoprotegerin (OPG) and a 10-fold elevated expression of the receptor activator of NF- $k B$ ligand (RANKL), indicating an increased bone turnover. These findings demonstrated that amlodipine accelerated fracture healing by stimulating bone formation, callus remodelling and osteoclast activity.
\end{abstract}

Keywords: Amlodipine, bone healing, fracture repair, NF-kB ligand, mice.

"Address for correspondence: Maximilian Menger, Department of Trauma and Reconstructive Surgery, Eberhard Karls University Tübingen, BG Trauma Center Tübingen, 72076 Tübingen, Germany.

Telephone number: +4968411626550 Email: mmenger@bgu-tuebingen.de

Copyright policy: This article is distributed in accordance with Creative Commons Attribution Licence (http://creativecommons.org/licenses/by-sa/4.0/).

\section{Introduction}

Hypertension is one of the major challenges for the public health care system, as it continues to be a critical contributor to the global burden of disease and mortality, leading to 9.4 million deaths each year (Oparil et al., 2018). An appropriate hypertension treatment with antihypertensive agents provides a better quality of life and substantially decreases both morbidity and mortality (Elliott et al., 2007). Drugs that are among the primary choices of hypertension treatment include calcium channel blockers (CCBs). They act by blocking the voltagedependent calcium channels in arteriolar smooth muscle cells, thus reducing the peripheral vascular resistance and, as a consequence, blood pressure (Katz et al., 1984). However, since CCBs interfere with the transportation of calcium through cell membranes, they may affect a range of metabolic processes, including bone metabolism (Duriez et al., 1990). In fact, various clinical and experimental studies suggest that CCBs influence skeletal calcium metabolism due to the presence of L-type channels in osteoblastic cells (Shimizu et al., 2012). Amlodipine, a dihydropyridine-type CCB of the third generation, was developed to improve the therapeutic efficiency of this class of drugs and, simultaneously, decreasing the frequency of adverse effects (Clement et al., 1994). 
Nonetheless, some authors reported an adverse effect of amlodipine on the process of bone regeneration. Teófilo et al. (2001) evaluated the effect of the chronic use of amlodipine on dental alveolar repair and observed a significantly delayed healing after tooth extraction. Moreover, Moraes et al. (2011), using a rat bone defect model of the mandibular ramus, revealed that amlodipine delays the repair process and compromises the formation of new bone tissue.

Amlodipine exerts cyto-protective effects from oxidative stress (Choi et al., 2014; Park et al., 2019) and hypoxia-induced apoptosis (Nehra et al., 2014). In addition, amlodipine treatment significantly increases the in vitro mineralisation of the osteoblastic cell line MC3T3-E1 (Nishiya et al., 2001) and mitigates the negative effects of orchidectomy by enhancing bone mineral density in rats (Gradosova et al., 2012). While there are controversial data on whether amlodipine benefits or impairs bone metabolism, there is a complete lack of data on whether this antihypertensive drug influences the process of long-bone healing after fracture. Therefore, the effect of amlodipine on fracture healing was studied in a standardised, stable closed femur fracture model in mice.

\section{Materials and Methods}

\section{Animals and drugs}

A total number of 60 CD-1 mice 12-16 weeks old were used. They were kept on a $12 \mathrm{~h}$ light/dark cycle and fed a standard pellet diet and water ad libitum. All animal procedures were performed according to the National Institutes of Health guidelines for the use of experimental animals and the German legislation on the protection of animals. Experiments were approved by the local governmental animal protection committee. Animals were divided into 3 groups of 20 mice each and treated daily with amlodipine (Pfizer) low dose [ $1 \mathrm{mg} / \mathrm{kg}$ body weight $(\mathrm{BW})]$, amlodipine high dose ( $3 \mathrm{mg} / \mathrm{kg} \mathrm{BW})$ or vehicle [ $\mathrm{NaCl}$, control (Ctrl)] post operatively using a gavage. All animals were included in the analysis. The dosages of $1 \mathrm{mg} / \mathrm{kg}$ and $3 \mathrm{mg} / \mathrm{kg} \mathrm{BW}$ used in the present study corresponded to those used in previous experimental studies (Halici et al., 2008; Zivna et al., 2018).

\section{Surgical procedure}

Mice were anaesthetised by intraperitoneal injection of xylazine $(25 \mathrm{mg} / \mathrm{kg} \mathrm{BW})$ and ketamine $(75 \mathrm{mg} / \mathrm{g}$ $\mathrm{BW})$. To evaluate the effect of amlodipine on fracture healing in mice, a well-established stable closed femoral fracture model, including intramedullary fixation with the MouseScrew (AO Foundation, Research Implants System, Davos, Switzerland), was used (Fig. 1a). Under aseptic conditions, a medial parapatellar incision was performed at the right knee and the patella was dislocated laterally
(Fig. 1b). After drilling a hole (diameter $0.5 \mathrm{~mm}$ ) into the intercondylar notch, an injection needle with a diameter of $0.4 \mathrm{~mm}$ was implanted through the intramedullary canal (Fig. 1c). Subsequently, a tungsten guidewire (diameter $0.2 \mathrm{~mm}$ ) was inserted through the intramedullary canal. After removal of the needle, the femur was fractured using a 3-point bending device (Fig. 1d) and an intramedullary medical stainless-steel screw $(18 \mathrm{~mm}$ length, $0.5 \mathrm{~mm}$ diameter) was implanted over the guidewire to stabilise the fracture (Holstein et al., 2009) (Fig. 1e). After fixation of the fracture, the wound was closed using 6-0 synthetic sutures (Fig. 1f). Fracture reduction and implant position were confirmed by radiography (Fig. 1g). Due to the highly standardised procedures, none of the animals had to be excluded from the present study.

\section{Radiological analysis}

At the end of the 2- and 5-week observation periods, the animals were re-anaesthetised and ventro-dorsal X-rays (MX-20, Faxitron X-ray Corporation) of the healing femora were performed. Fracture healing was analysed according to the classification of Goldberg, with stage 0 indicating radiological nonunion, stage 1 indicating possible union and stage 2 indicating radiological union (Goldberg et al., 1985).

\section{Biomechanical analysis}

For biomechanical analysis, the right and left femora were resected at 2 ( $n=8$ each group) and 5 weeks $(n=8$ each group) and freed from soft tissue. After removing the implants, callus stiffness was measured using a three-point bending device (Mini-Zwick Z 2.5; Zwick, Ulm, Germany). Due to the different stages of healing, the loads which had to be applied varied markedly between the individual animals. Loading was stopped individually in every case when the actual load-displacement curve deviated more than $1 \%$ from linearity (Schoen et al., 2008). To guarantee standardised measuring conditions, femora were always mounted ventral aspect upwards. A working gauge length of $6 \mathrm{~mm}$ was used. Applying a gradually increasing bending force of $1 \mathrm{~mm} / \mathrm{min}$, the bending stiffness $(\mathrm{N} / \mathrm{mm})$ was calculated from the linear elastic part of the load displacement diagram. Macroscopical and microscopical (histology) assessment was performed to ensure that the load was not destructive. To account for differences in bone stiffness in the individual animals, the unfractured left femora were also analysed, serving as internal controls. All values of the fractured femora are given as absolute values and percentages of the corresponding unfractured femora.

\section{Histomorphometric analysis}

For histological analysis, bones were fixed in IHC zinc fixative (BD Pharmingen, San Diego, CA, USA) for $24 \mathrm{~h}$, decalcified in $13 \%$ ethylenediaminetetraacetic acid (EDTA) solution for 2 weeks and embedded 
in paraffin-wax. Longitudinal sections of $5 \mu \mathrm{m}$ thickness were stained according to the trichrome method. Structural indices were calculated using light microscopy with a 1.25× lens (Olympus BX60 Microscope; Zeiss Axio Cam and Axio Vision 3.1) according to the suggestion provided by Gerstenfeld et al. (2005) using the ImageJ Analysis System (NIH, Bethesda, MD, USA). These included bone (total osseous tissue) callus area/total callus area [TOTAr/ CAr (\%)], cartilaginous callus area/total callus area [CgAr/CAr (\%)] and fibrous tissue callus area/total callus area [FTAr/CAr (\%)].

\section{Western blot analysis}

Protein expression within the callus tissue was determined by Western blot analysis, including the expression of morphogenetic protein-2 (BMP-2) and
-4 (BMP-4), cysteine-rich protein (CYR) 61, vascular endothelial growth factor (VEGF), osteoprotegerin $(\mathrm{OPG})$ and receptor activator of $N F-\kappa B$ ligand (RANKL). The callus tissue was frozen and stored at $-80{ }^{\circ} \mathrm{C}$ until required. Analyses of callus tissue were performed 2 weeks after fracture healing ( $n=4$ each group). After saving the whole-protein fraction, the blotting procedure and protein detection was performed using the following antibodies: goat anti-mouse BMP-2/BMP-4 (1 : 100, R\&D Systems, AF355), sheep anti-mouse CYR61 (1 : 100, R\&D Systems, AF4055), rabbit anti-mouse VEGF (1 : 300, Abcam, ab3109), rabbit anti-mouse OPG (1 : 300, Bioss by Biozol, Eching, Germany, BS0431R) and rabbit anti-mouse RANKL (1:300, Abcam, ab625616). Primary antibodies were followed by corresponding horseradish peroxidase-conjugated secondary
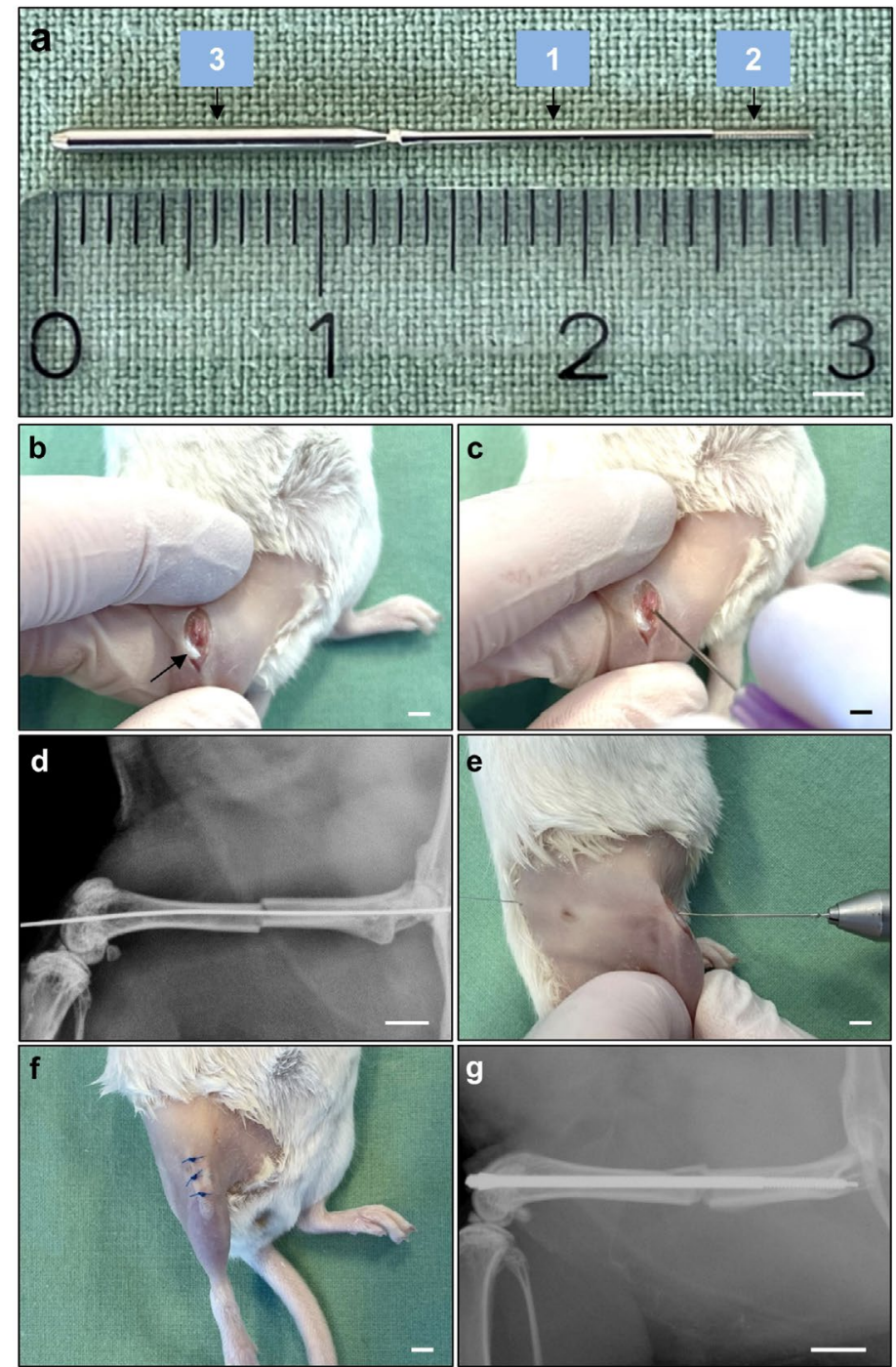

Fig. 1. Surgical procedure. (a) Illustration of the intramedullary MouseScrew with (1) a distal thread and (2) a cone-shaped head with (3) torque-dependent break point, which can be connected to a screwholder. (b) A medial parapatellar incision was performed at the right knee and the patella (arrow) was dislocated laterally. (c) After drilling a hole (diameter of $0.5 \mathrm{~mm}$ ) into the intercondylar notch, an injection needle with a diameter of $0.4 \mathrm{~mm}$ was implanted through the intramedullary canal. (d) Subsequently, a tungsten guidewire (diameter of $0.2 \mathrm{~mm}$ ) was inserted through the intramedullary canal and the femur was fractured by a 3-point bending device. (e) The MouseScrew was implanted over the guidewire to stabilise the fracture. (f) After fixation of the fracture, the wound was closed using 6-0 synthetic sutures. (g) Fracture reduction and implant position were confirmed by radiography. Scale bars: $2 \mathrm{~mm}$. 
antibodies (1.5 h, 1 : 1,000, R\&D Systems, HAF008). Protein expression was visualised by means of luminol-enhanced chemiluminescence after exposure of the membrane to the Intas ECL Chemocam Imager (Intas Science Imaging Instrument $\mathrm{GmbH}$, Göttingen, Germany) and normalised to $\beta$-actin signals $(1: 5,000$, mouse anti-mouse $\beta$-actin, Sigma-Aldrich, A5441) to correct for unequal loading.

\section{Statistical analysis}

Data were tested for normal distribution and equal variance. Then, differences between the groups were assessed by one-way analysis of variance (one-way ANOVA). This was followed by Student-NewmanKeuls post-hoc test, including the correction of the alpha-error to compensate for multiple comparisons (SigmaPlot 13.0; Jandel Corporation, San Rafael, CA, USA). All values are expressed as mean \pm SEM. Statistical significance was accepted for $p<0.05$.

\section{Results}

\section{Radiological analysis}

2 and 5 weeks after fracture healing, radiological analysis revealed a higher Goldberg score in amlodipine low-dose-treated and high-dose-treated animals when compared to vehicle-treated controls (Fig. 2a-h). However, this difference was not statistically significant $(p>0.05)$.

\section{Biomechanical analysis}

Biomechanical analysis of the femora 2 and 5 weeks after fracture showed a slight but not significant increase in bending stiffness in amlodipine lowdose-treated and high-dose-treated animals when compared to vehicle-treated controls (Fig. 3a-d). Of note, comparison of the bending stiffness of the contralateral femora did not show any significant differences between vehicle-, amlodipine low-dose- and amlodipine high-dose-treated animals $2(119.1 \pm 18.2 \mathrm{~N} / \mathrm{mm}$ vs. $111.4 \pm 10.2 \mathrm{~N} /$ $\mathrm{mm}$ vs. $142.5 \pm 13.2 \mathrm{~N} / \mathrm{mm}$, respectively) and 5 weeks $(125.6 \pm 10.3 \mathrm{~N} / \mathrm{mm}$ vs. $136.8 \pm 6.6 \mathrm{~N} / \mathrm{mm}$ vs. $140.5 \pm 6.7 \mathrm{~N} / \mathrm{mm}$, respectively) after fracture. Therefore, it is possible to conclude that 5 weeks amlodipine low-dose and high-dose treatment did not affect the quality of non-fractured bone.

\section{Histological analysis}

The histological analysis revealed in all three study groups a typical callus formation of secondary fracture healing, including intramembranous and endochondral ossification (Fig. 4a-f). 2 weeks after
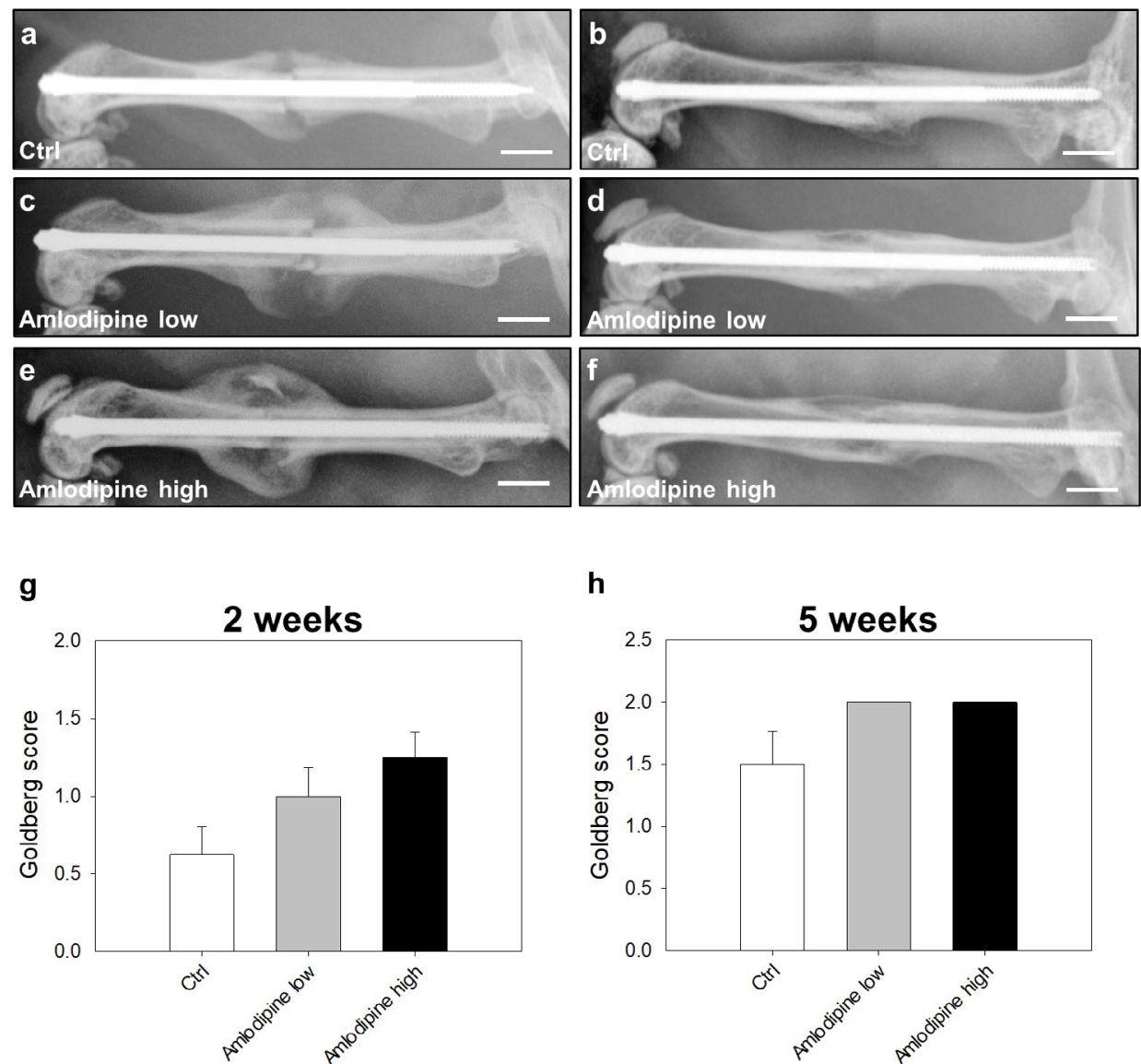

Fig. 2. Radiographic analysis. Radiographs of the femora of $(\mathbf{a}, \mathbf{b})$ vehicle-treated controls, $(\mathbf{c}, \mathbf{d})$ amlodipine low-dose-treated animals and (e,f) amlodipine high-dose-treated animals (a,c,e) 2 and $(\mathbf{b}, \mathbf{d}, \mathbf{f}) 5$ weeks after fracture healing. Scale bar: $2 \mathrm{~mm}$. Goldberg score of vehicle-treated controls (white bars, $n=8$ ), amlodipine low-dose-treated animals (grey bars, $n=8$ ) and amlodipine high-dose-treated animals (black bars, $n=8$ ) (g) 2 weeks and (h) 5 weeks after fracture healing. Mean \pm SEM. 
fracture, the amount of bone tissue within the callus was significantly larger in amlodipine low-dose- and high-dose-treated animals when compared to vehicletreated controls (Fig. 4g). Vice versa, the amount of cartilaginous tissue was significantly smaller when compared to vehicle-treated controls (Fig. 4i). The analysis of the amount of fibrous tissue showed no significant differences between the three study groups (Fig. 4k). 5 weeks after fracture healing, the amount of bone tissue within the callus was still significantly enhanced in amlodipine low-doseand high-dose-treated animals when compared to controls (Fig. 4h). In vehicle-treated controls there was only a small, remnant amount of cartilaginous tissue detectable, while in amlodipine low-dose- and high-dose-treated animals there was a complete lack of cartilaginous tissue within the callus (Fig. 4j). Of interest, 5 weeks after fracture, fibrous tissue was still $\sim 15 \%$ in vehicle-treated controls, whereas it was almost zero in amlodipine low-dose- and high-dosetreated animals (Fig. 41).

\section{Western blot analysis}

After 2 weeks of fracture healing, the Western blot analysis of the callus tissue revealed that amlodipine low-dose- and high-dose-treatment significantly increased the expression of BMP-2, when compared to vehicle-treated controls (Fig. 5a,b). In addition, amlodipine treatment also increased the callus expression of BMP-4. However, the difference compared to controls was not statistically significant (Fig. 5a,c).

a

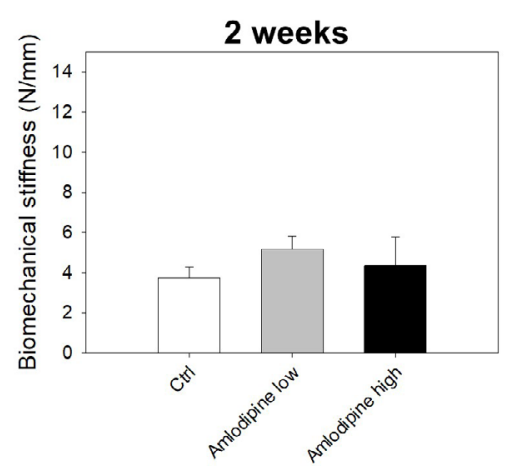

C

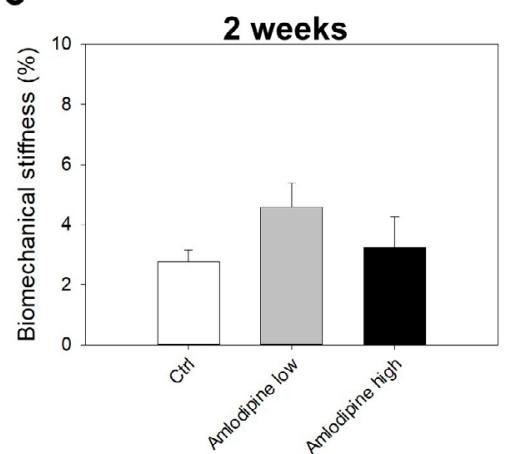

The Western blot analyses of the osteogenic and angiogenic growth factors CYR61 and VEGF showed a slightly higher expression of CYR61 and a significantly higher expression of VEGF in amlodipine high-dose-treated animals when compared to amlodipine low-dose- and vehicletreated animals (Fig. 5d-f).

Of interest, the expression of OPG, an inhibitor of osteoclastogenesis, was almost 2-fold higher in amlodipine low-dose-treated animals $(12.7 \pm 2.2)$ and over 4-fold higher in amlodipine high-dose-treated animals $(32.6 \pm 5.5)$ when compared to vehicletreated controls $(7.4 \pm 2.3)$ (Fig. 6a, b). The expression of RANKL, a stimulator of osteoclastogenesis, was even 4-fold higher in amlodipine low-dose-treated animals (3.1 \pm 0.8$)$ and $\sim 8$-fold higher in amlodipine high-dose-treated animals $(5.7 \pm 1.1)$ when compared to vehicle-treated controls $(0.7 \pm 0.1)$ (Fig. 6a,c). This resulted in a lower OPG/RANKL-ratio in both amlodipine treatment groups when compared to controls (Fig. 6d).

\section{Discussion}

The present study analysed the effect of amlodipine treatment on fracture healing. The data of the study demonstrated, for the first time, that amlodipine accelerated bone healing by inducing bone neoformation within the callus tissue. The accelerated bone healing in amlodipine-treated animals was associated with a slight increase in bending stiffness,

\section{b}
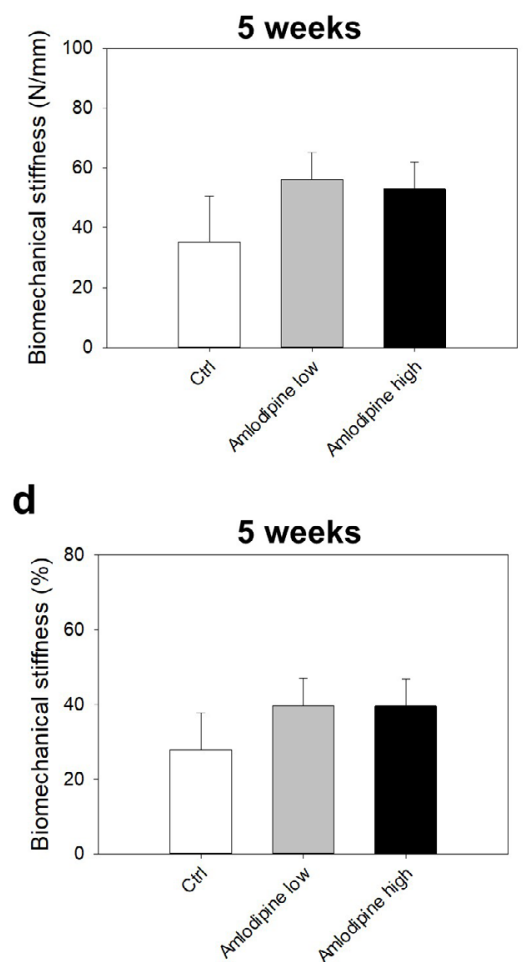

Fig. 3. Biomechanical analysis. Biomechanical analysis of mouse femora $(\mathbf{a}, \mathbf{c}) 2$ weeks and (b,d) 5 weeks after fracture healing in vehicle-treated controls (white bars, $n=8$ ), amlodipine low-dose-treated animals (grey bars, $n=8$ ) and amlodipine high-dose-treated animals (black bars, $n=8)$. Data are given in $(\mathbf{a}, \mathbf{b})$ absolute values and $(\mathbf{c}, \mathbf{d})$ percentage of the non-fractured contralateral femora. Mean \pm SEM. 


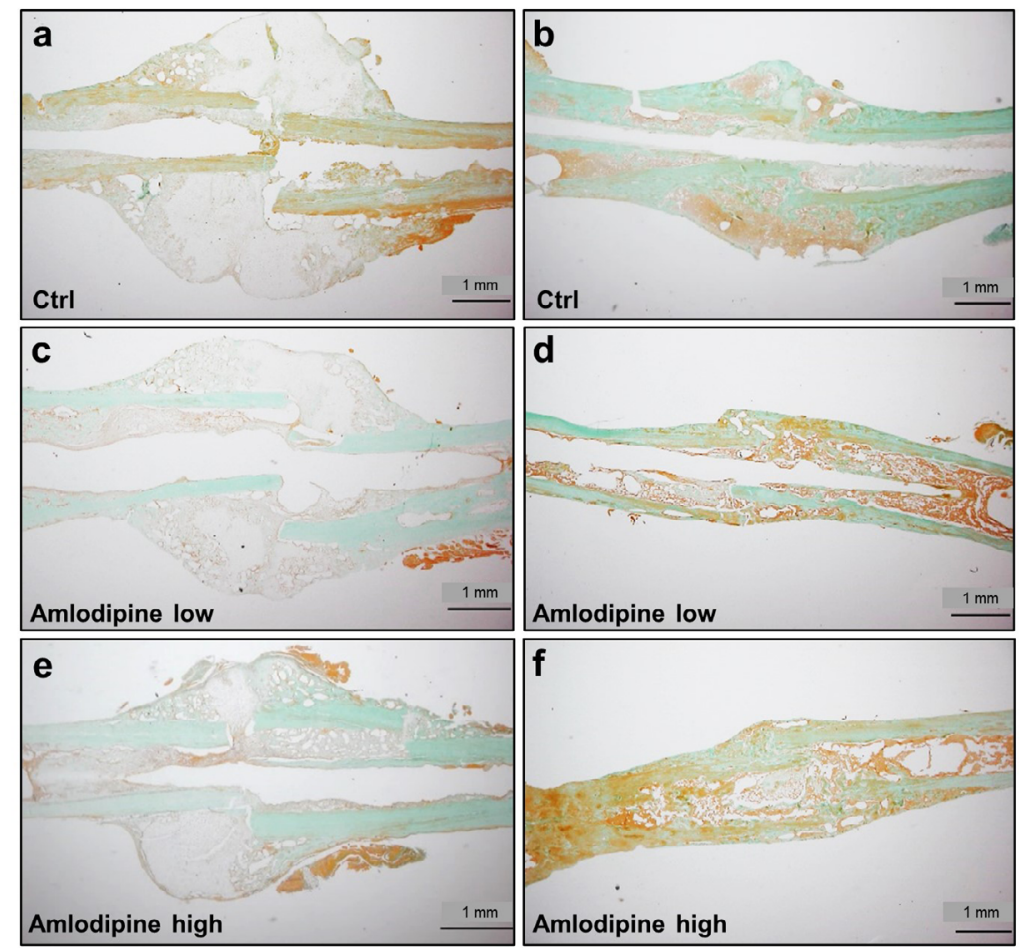

g

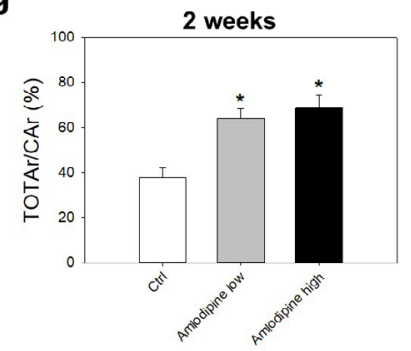

i

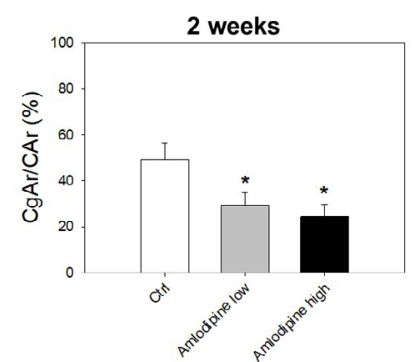

k

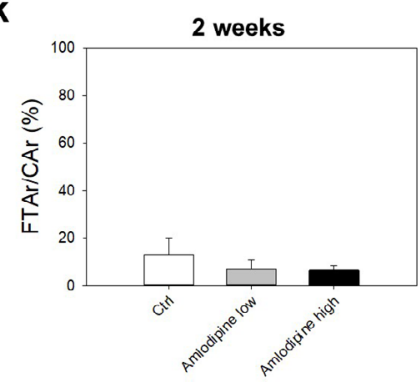

h

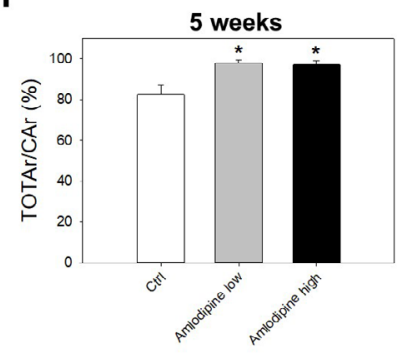

j

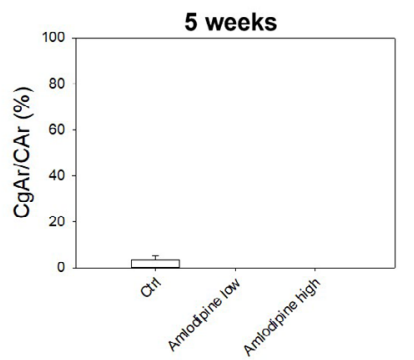

I

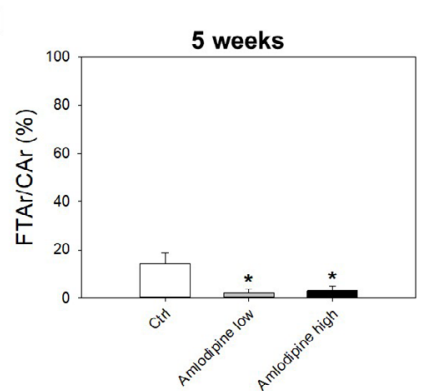

Fig. 4. Histological analysis. Representative histological sections (Masson-Goldner staining) (a,c,e) 2 weeks and $(\mathbf{b}, \mathbf{d}, \mathbf{f}) 5$ weeks after fracture healing in $(\mathbf{a}, \mathbf{b})$ vehicle-treated controls, $(\mathbf{c}, \mathbf{d})$ amlodipine lowdose-treated animals and $(\mathbf{e}, \mathbf{f})$ amlodipine high-dose-treated animals. Histomorphometric analysis of the tissue distribution within the callus, including $(\mathbf{g}, \mathbf{h})$ total osseous tissue callus area/total callus area (TOTAr/ $\mathrm{CAr}, \%),(\mathbf{i}, \mathbf{j})$ cartilaginous callus area/total callus area $(\mathrm{CgAr} / \mathrm{CAr}, \%)$ and $(\mathbf{k}, \mathbf{l})$ fibrous tissue callus area/ total callus area (FTAr/CAr, \%) (g,i,, $\mathbf{k}) 2$ weeks and $(\mathbf{h}, \mathbf{j}, \mathbf{l}) 5$ weeks after fracture healing in vehicle-treated controls (white bars, $n=8$ ), amlodipine low-dose-treated animals (grey bars, $n=8$ ) and amlodipine highdose-treated animals (black bars, $n=8$ ). Mean \pm SEM; ${ }^{*} p<0.05$ vs. control (Ctrl). 
an enhanced expression of the osteogenic factors BMP-2 and BMP-4 as well as an elevated expression of the angiogenic factor VEGF. Of note, no significant differences were found in callus composition between amlodipine low-dose- and amlodipine high-dosetreated animals. This indicated that the low dose of amlodipine $(1 \mathrm{mg} / \mathrm{kg} \mathrm{BW})$ used in the present study was sufficient to accelerate the process of bone healing. In addition, amlodipine treatment, in particular the high-dose treatment, also accelerated bone turnover, as indicated by increased levels of OPG and RANKL within the callus tissue. These data supported the view that amlodipine also accelerated callus remodelling.

CCBs are widely used drugs for the treatment of hypertension as well as vasospasm and chronic stable angina pectoris. Clinical trials confirmed that they can prevent cardiovascular events by lowering the blood pressure (Civantos et al., 2004). Amlodipine, a dihydropyridine-type CCB, acts by inhibiting calcium entry through voltage-gated transmembrane L-type channels. This leads to a decrease in the intracellular calcium concentration and a subsequent relaxation of smooth muscle cells in the coronary and peripheral

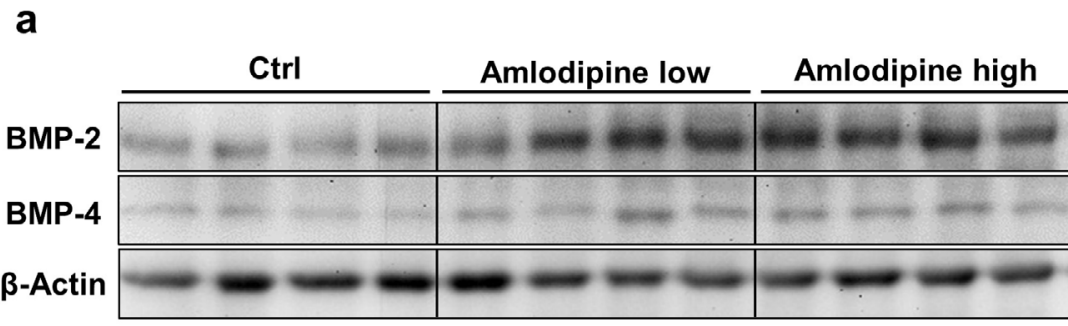

b

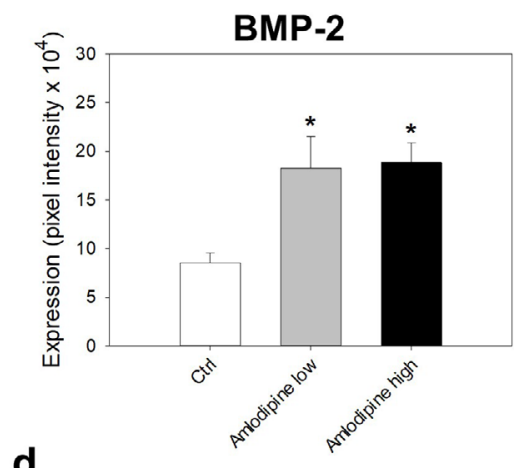

C

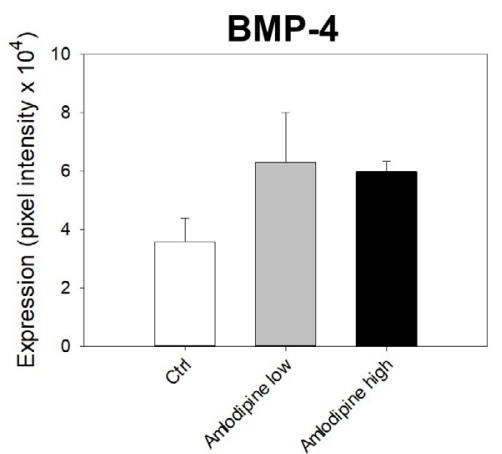

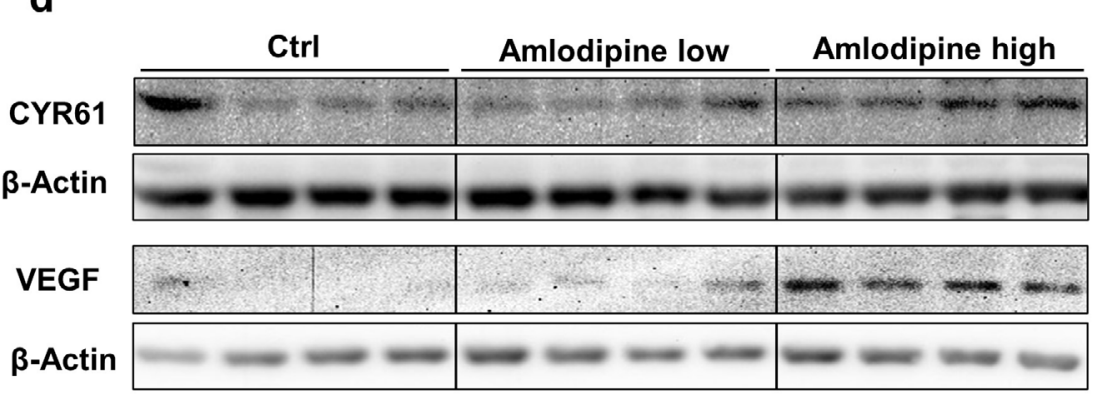
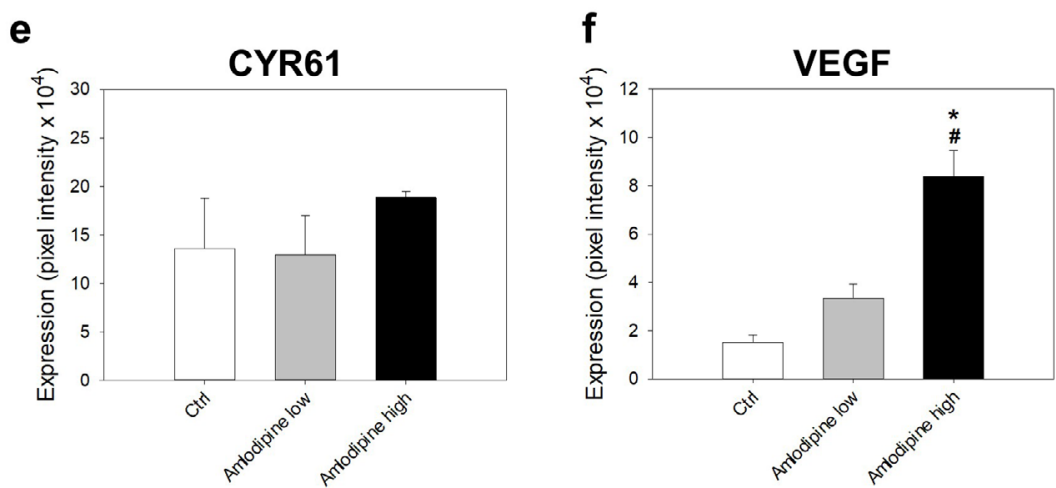

Fig. 5. Western blot analysis (1). Western blot analysis of (a,b) BMP-2, (a,c) BMP-4, (d,e) CYR61 and (d,f) VEGF expression in the callus tissue of vehicle-treated controls (white bars, $n=4$ ), amlodipine low-dosetreated animals (grey bars, $n=4$ ) and amlodipine high-dose-treated animals (black bars, $n=4$ ) 2 weeks after fracture healing. Mean \pm SEM; ${ }^{*} p<0.05$ vs. control (Ctrl); ${ }^{\#} p<0.05$ vs. amlodipine low. 
vessels (Devabhaktuni et al., 2009). Of note, several studies have reported an effect of amlodipine on bone metabolism. Halici et al. (2008) demonstrated that amlodipine protects against ovariectomyinduced bone loss. Furthermore, Karakus et al. (2016) showed in an experimental ovariectomised and inflammation-induced osteoporosis rat model that amlodipine does not only prevent the ovariectomyand inflammation-induced loss of the osteogenic factors runt-related transcription factor 2 (Runx2) and type I collagen 1a1 (Col1a1) but even induces a 3- to 4-fold elevation of Runx2 and Col1a1 expression when compared to non-osteoporotic controls. Accordingly, the authors proposed that amlodipine may be used as a therapeutic agent for osteoporosis treatment in hypertensive patients (Karakus et al., 2016).

The increased bone tissue formation and accelerated fracture healing observed in the present study after amlodipine treatment may be caused by the enhanced expression of BMP-2 and BMP-4. During bone formation, BMPs are secreted by osteoblasts within the extracellular matrix (McBride et al., 2014). Interestingly, Nishiya et al. (2001) demonstrated that dihydropyridine-type CCBs by blocking L-type calcium channels increase osteoblast differentiation, alkaline phosphatase activity and mineralisation in vitro. Therefore, it is possible that the enhanced expression of BMPs is mediated by an amlodipineinduced stimulation of osteoblast differentiation and activity. As a member of the transforming growth factor- $\beta$ superfamily, BMP- 2 induces bone formation in vivo by promoting differentiation of mesenchymal stem cells and osteoprogenitor cells into osteoblasts (Cheng et al., 2003; Mi et al., 2013). Several studies have demonstrated that the application of BMP2 also accelerates and improves bone healing in experimental murine animal models (Orth et al., 2017; Schmidmaier et al., 2002). Further analysis of the molecular pathways of BMP-2 revealed that it acts through various autocrine and paracrine mechanisms, such as the secretion of basic fibroblast growth factor (Rivera et al., 2013).

BMP-4, on the other hand, mainly increases the secretion of VEGF (Rivera et al., 2013). Accordingly, an enhanced expression of VEGF was found in amlodipine-treated animals. VEGF is a key regulator of physiological angiogenesis during embryogenesis and skeletal growth and is also associated with pathological angiogenesis in tumours (Carmeliet et al., 2000). More importantly, VEGF plays a crucial role in bone healing, because the vascularisation is necessary for a successful healing process, providing an adequate nutrient supply and the infiltration of vital progenitor cells for callus remodelling (Carano et al., 2003). The importance of a sufficient vascularisation is supported by experimental studies demonstrating that an inhibition of VEGF signalling leads to an impaired bone healing and non-union formation (Hausman et al., 2001). Moreover, treatment with VEGF significantly improves bone healing in animal models (Li et al., 2009). Hence, the elevated secretion of VEGF, observed in amlodipine-treated

a
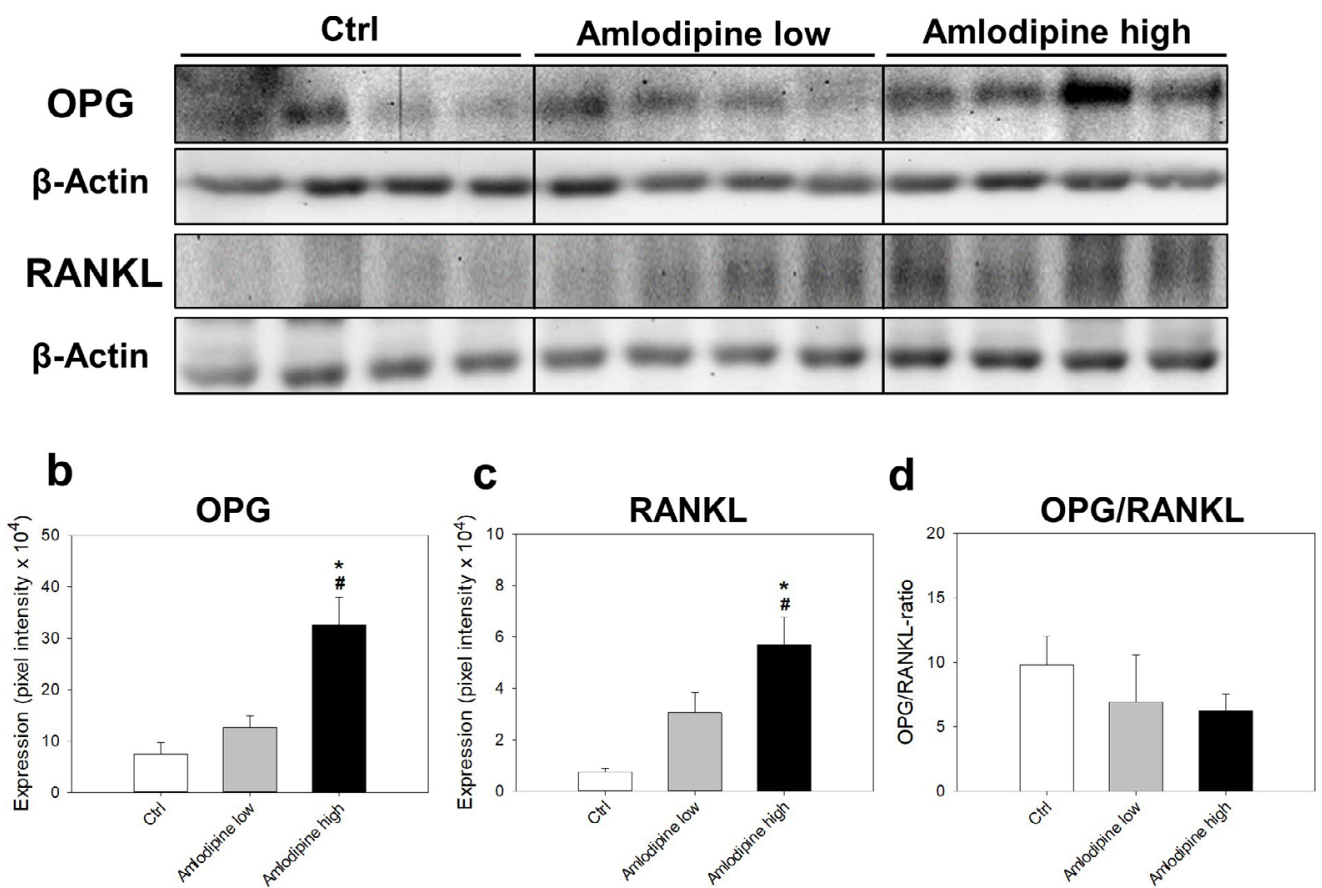

Fig. 6. Western blot analysis (2). Western blot analysis of (a,b) OPG and (a,c) RANKL expression in the callus tissue of vehicle-treated controls (white bars, $n=4$ ), amlodipine low-dose-treated animals (grey bars, $n=4$ ) and amlodipine high-dose-treated animals (black bars, $n=4) 2$ weeks after fracture healing. (d) OPG/ RANKL-ratio in vehicle-treated controls (white bars, $n=4$ ), amlodipine low-dose-treated animals (grey bars, $n=4$ ) and amlodipine high-dose-treated animals (black bars, $n=4) 2$ weeks after fracture healing. Means \pm SEM; ${ }^{*} p<0.05$ vs. Ctrl; ${ }^{*} p<0.05$ vs. amlodipine low. 
animals, may have contributed to the accelerated fracture healing.

CYR61 plays an important role in the process of bone healing by the stimulation of osteoblast differentiation and proliferation (Si et al., 2006). The protein acts as an extracellular signalling molecule in human bone, regulated by $1 \alpha, 25$-dihydroxyvitamin D3 (Lechner et al., 2000). Frey et al. (2012) demonstrated in a rabbit trauma model that the local application of CYR61 improves callus regeneration, as indicated by an increased bone formation and torsional strength. In line with this, selective inhibition of phosphodiesterase-3 (PDE-3) and PDE-5 accelerates fracture healing through a CYR61-associated pathway (Herath et al., 2015; Histing et al., 2011). In the present study, however, CYR61 was not increased in amlodipine low-dose-treated animals and only slightly increased in amlodipine high-dose-treated animals. Because there was also no difference in bone formation between the animals of the two amlodipine treatment groups, it is reasonable to think that CYR61 did not play a major role in the amlodipine-induced acceleration of fracture healing.

RANKL is a potent activator of bone resorption by binding RANK on the osteoclast cell membrane. On the other hand, OPG is a soluble decoy receptor for RANKL that interferes with RANKL-RANK binding, leading to an inhibition of osteoclastogenesis (Lacey et al., 1998; Simonet et al., 1997). Cartilage resorption during fracture healing is associated with a peak in RANKL and OPG expression (Gerstenfeld et al., 2009). Furthermore, inhibition of RANKL through treatment with melatonin and pantoprazole delays the process of bone remodelling and leads to an impaired fracture healing in mice (Histing et al., 2012a; 2012b). This emphasises that successful bone healing requires osteoclast-mediated cartilage and bone resorption. In the present study, amlodipine treatment induced an increase in OPG expression and an even more pronounced increase in RANKL expression, resulting in a reduced OPG/RANKLratio in amlodipine low-dose- and high-dosetreated animals. Hence, amlodipine treatment may stimulate the RANKL-mediated cartilage and bone resorption by osteoclasts, resulting in an increase in bone turnover. This explains the significantly smaller amounts of cartilaginous and fibrous tissue in amlodipine-treated animals that were observed in the histomorphometric analysis.

Interestingly, these findings contradict previous studies investigating the effect amlodipine on bone metabolism and osteoporosis (Karakus et al., 2016; Ushijima et al., 2010). Ushijima et al. (2010) postulated that amlodipine prevents a reduction in bone mineral density in stroke-prone spontaneously hypertensive rats through an inhibition of osteoclast activity. The authors assumed that the reduction in osteoclast function was caused by the binding of amlodipine to osteoclast calcium channels, resulting in an increased intracellular calcium concentration (Ritchie et al., 1994). However, it should be considered that the process of callus remodelling during fracture healing is a carefully organised process between the formation of new bone tissue by osteoblasts and the resorption of cartilage and bone by osteoclasts (Teitelbaum et al., 2007). Moreover, it is widely accepted that osteoblasts express RANKL and, thus, stimulate osteoclastogenesis themselves (Chen et al., 2018). Therefore, it is the authors' opinion that the acceleration in fracture healing in amlodipine-treated animals was caused in part through an activation of osteoclasts, which was mediated by an amlodipineinduced osteoblast differentiation.

Some studies reported a negative effect of amlodipine on dental alveolar repair and healing of mandibular bone defects (Moraes et al., 2011; Teofilo et al., 2001). A possible explanation for these results contradicting the present study may be the fact that facial bones heal with more intramembranous ossification and less endochondral bone formation, whereas long tubular bones, such as the femur, heal mainly by endochondral ossification (Yu et al., 2012). The beneficial effects of amlodipine on fracture healing, as observed in the present study, were mainly due to an increased cartilage resorption and bone turnover. During intramembranous healing of facial bones, however, amlodipine may have different and even adverse effects on regeneration as observed by Moraes et al. (2011) and Teófilo et al. (2001).

Taken together, the results indicated that amlodipine treatment accelerated fracture healing and callus remodelling through upregulation of BMP-2 and VEGF as well as through an increased OPG/RANKL-mediated bone turnover.

\section{Acknowledgements}

We are grateful for the excellent technical assistance of Janine Becker and Julia Parakenings.

The authors thank Servier Medical Art for providing access to designed medical elements (https://smart.servier.com/), supporting the generation of the graphical abstract of this publication.

\section{References}

Carano RA, Filvaroff EH (2003) Angiogenesis and bone repair. Drug Discov Today 8: 980-989.

Carmeliet P, Jain RK (2000) Angiogenesis in cancer and other diseases. Nature 407: 249-257.

Chen X, Wang Z, Duan N, Zhu G, Schwarz EM, Xie C (2018) Osteoblast-osteoclast interactions. Connect Tissue Res 59: 99-107.

Cheng H, Jiang W, Phillips FM, Haydon RC, Peng Y, Zhou L, Luu HH, An N, Breyer B, Vanichakarn P, Szatkowski JP, Park JY, He TC (2003) Osteogenic activity of the fourteen types of human bone morphogenetic proteins (BMPs). J Bone Joint Surg Am 85: 1544-1552. 
Choi NY, Choi H, Park HH, Lee EH, Yu HJ, Lee KY, Joo Lee Y, Koh SH (2014) Neuroprotective effects of amlodipine besylate and benidipine hydrochloride on oxidative stress-injured neural stem cells. Brain Res 1551: 1-12.

Civantos B, Aleixandre A (2004) Blood pressure and alpha-vascular reactivity in hypertensive rats treated with amlodipine and dietary Ca. Eur J Pharmacol 489: 101-110.

Clement DL, De Buyzere M, Duprez D (1994) Antihypertensive effects of calcium antagonists. Clinical facts and modulating factors. Am J Hypertens 7: 16S-22S.

Devabhaktuni M, Bangalore S (2009) Fixed combination of amlodipine and atorvastatin in cardiovascular risk management: patient perspectives. Vasc Health Risk Manag 5: 377-387.

Duriez J, Flautre B, Blary MC, Duriez R (1990) [Effect of a calcium inhibitor, verapamil, on the development of heterotopic ossifications. An experimental study in rats]. Int Orthop 14: 415-421.

Elliott WJ (2007) Systemic hypertension. Curr Probl Cardiol 32: 201-259.

Frey SP, Doht S, Eden L, Dannigkeit S, Schuetze N, Meffert RH, Jansen H (2012) Cysteine-rich matricellular protein improves callus regenerate in a rabbit trauma model. Int Orthop 36: 2387-2393.

Gerstenfeld LC, Wronski TJ, Hollinger JO, Einhorn TA (2005) Application of histomorphometric methods to the study of bone repair. J Bone Miner Res 20: 17151722.

Gerstenfeld LC, Sacks DJ, Pelis M, Mason ZD, Graves DT, Barrero M, Ominsky MS, Kostenuik PJ, Morgan EF, Einhorn TA (2009) Comparison of effects of the bisphosphonate alendronate versus the RANKL inhibitor denosumab on murine fracture healing. J Bone Miner Res 24: 196-208.

Goldberg VM, Powell A, Shaffer JW, Zika J, Bos GD, Heiple KG (1985) Bone grafting: role of histocompatibility in transplantation. J Orthop Res 3: 389-404.

Gradosova I, Zivna H, Palicka V, Hubena S, Svejkovska K, Zivny P (2012) Protective effect of amlodipine on rat bone tissue after orchidectomy. Pharmacology 89: 37-43.

Halici Z, Borekci B, Ozdemir Y, Cadirci E, Suleyman H (2008) Protective effects of amlodipine and lacidipine on ovariectomy-induced bone loss in rats. Eur J Pharmacol 579: 241-245.

Hausman MR, Schaffler MB, Majeska RJ (2001) Prevention of fracture healing in rats by an inhibitor of angiogenesis. Bone 29: 560-564.

Herath SC, Lion T, Klein M, Stenger D, Scheuer C, Holstein JH, Morsdorf P, Rollmann MF, Pohlemann T, Menger MD, Histing T (2015) Stimulation of angiogenesis by cilostazol accelerates fracture healing in mice. J Orthop Res 33: 1880-1887.

Histing T, Marciniak K, Scheuer C, Garcia P, Holstein JH, Klein M, Matthys R, Pohlemann T, Menger MD (2011) Sildenafil accelerates fracture healing in mice. J Orthop Res 29: 867-873.
Histing T, Anton C, Scheuer C, Garcia P, Holstein JH, Klein M, Matthys R, Pohlemann T, Menger MD (2012a) Melatonin impairs fracture healing by suppressing RANKL-mediated bone remodeling. J Surg Res 173: 83-90.

Histing T, Stenger D, Scheuer C, Metzger W, Garcia P, Holstein JH, Klein M, Pohlemann T, Menger MD (2012b) Pantoprazole, a proton pump inhibitor, delays fracture healing in mice. Calcif Tissue Int 90: 507-514.

Holstein JH, Matthys R, Histing T, Becker SC, Fiedler M, Garcia P, Meier C, Pohlemann T, Menger MD (2009) Development of a stable closed femoral fracture model in mice. J Surg Res 153: 71-75.

Karakus E, Halici Z, Albayrak A, Bayir Y, Demirci E, Aydin A, Ozturk-Karagoz B, Cadirci E, Ayan AK, Sahin A, Unal D (2016) Effects of administration of amlodipine and lacidipine on inflammation-induced bone loss in the ovariectomized rat. Inflammation 39: 336-346.

Katz AM, Hager WD, Messineo FC, Pappano AJ (1984) Cellular actions and pharmacology of the calcium channel blocking drugs. Am J Med 77: 2-10.

Lacey DL, Timms E, Tan HL, Kelley MJ, Dunstan CR, Burgess T, Elliott R, Colombero A, Elliott G, Scully S, Hsu H, Sullivan J, Hawkins N, Davy E, Capparelli C, Eli A, Qian YX, Kaufman S, Sarosi I, Shalhoub V, Senaldi G, Guo J, Delaney J, Boyle WJ (1998) Osteoprotegerin ligand is a cytokine that regulates osteoclast differentiation and activation. Cell 93: 165176.

Lechner A, Schutze N, Siggelkow H, Seufert J, Jakob F (2000) The immediate early gene product hCYR61 localizes to the secretory pathway in human osteoblasts. Bone 27: 53-60.

Li R, Stewart DJ, von Schroeder HP, Mackinnon ES, Schemitsch EH (2009) Effect of cell-based VEGF gene therapy on healing of a segmental bone defect. J Orthop Res 27: 8-14.

McBride SH, McKenzie JA, Bedrick BS, Kuhlmann P, Pasteris JD, Rosen V, Silva MJ (2014) Long bone structure and strength depend on BMP2 from osteoblasts and osteocytes, but not vascular endothelial cells. PLoS One 9: e96862. DOI: 10.1371/ journal.pone.0096862.

Mi M, Jin H, Wang B, Yukata K, Sheu TJ, Ke QH, Tong P, Im HJ, Xiao G, Chen D (2013) Chondrocyte BMP2 signaling plays an essential role in bone fracture healing. Gene 512: 211-218.

Moraes RB, Correa L, Luz JG (2011) Adverse effects of the amlodipine on bone healing of the mandibular fracture: an experimental study in rats. Oral Maxillofac Surg 15: 93-101.

Nehra S, Bhardwaj V, Saraswat D (2014) Amlodipine protects rat ventricular cardiomyoblast H9c2 From hypoxia-induced apoptosis and restores oxidative balance by Akt-1-dependent manner. J Cardiovasc Pharmacol 64: 375-384.

Nishiya Y, Sugimoto S (2001) Effects of various antihypertensive drugs on the function of osteoblast. Biol Pharm Bull 24: 628-633. 
Oparil S, Acelajado MC, Bakris GL, Berlowitz DR, Cifkova R, Dominiczak AF, Grassi G, Jordan J, Poulter NR, Rodgers A, Whelton PK (2018) Hypertension. Nat Rev Dis Primers 4: 18014. DOI: 10.1038/nrdp.2018.14.

Orth M, Kruse NJ, Braun BJ, Scheuer C, Holstein JH, Khalil A, Yu X, Murphy WL, Pohlemann T, Laschke MW, Menger MD (2017) BMP-2-coated mineral coated microparticles improve bone repair in atrophic non-unions. Eur Cell Mater 33: 1-12.

Park HH, Han MH, Choi H, Lee YJ, Kim JM, Cheong JH, Ryu JI, Lee KY, Koh SH (2019) Mitochondria damaged by oxygen glucose deprivation can be restored through activation of the PI3K/Akt pathway and inhibition of calcium influx by amlodipine camsylate. Sci Rep 9: 15717. DOI: 10.1038/s41598-01952083-y.

Ritchie CK, Maercklein PB, Fitzpatrick LA (1994) Direct effect of calcium channel antagonists on osteoclast function: alterations in bone resorption and intracellular calcium concentrations. Endocrinology 135: 996-1003.

Rivera JC, Strohbach CA, Wenke JC, Rathbone CR (2013) Beyond osteogenesis: an in vitro comparison of the potentials of six bone morphogenetic proteins. Front Pharmacol 4: 125. DOI: 10.3389/ fphar.2013.00125.

Schmidmaier G, Wildemann B, Cromme F, Kandziora F, Haas NP, Raschke M (2002) Bone morphogenetic protein-2 coating of titanium implants increases biomechanical strength and accelerates bone remodeling in fracture treatment: a biomechanical and histological study in rats. Bone 30: 816-822.

Schoen M, Rotter R, Schattner S, Mittlmeier T, Claes L, Vollmar B, Gradl G (2008) Introduction of a new interlocked intramedullary nailing device for stabilization of critically sized femoral defects in the rat: a combined biomechanical and animal experimental study. J Orthop Res 26: 184-189.

Shimizu H, Nakagami H, Yasumasa N, Mariana OK, Kyutoku M, Koriyama H, Nakagami F, Shimamura M, Rakugi H, Morishita R (2012) Cilnidipine, but not amlodipine, ameliorates osteoporosis in ovariectomized hypertensive rats through inhibition of the N-type calcium channel. Hypertens Res 35: 77-81.

Si W, Kang Q, Luu HH, Park JK, Luo Q, Song WX, Jiang W, Luo X, Li X, Yin H, Montag AG, Haydon RC, He TC (2006) CCN1/Cyr61 is regulated by the canonical Wnt signal and plays an important role in Wnt3A-induced osteoblast differentiation of mesenchymal stem cells. Mol Cell Biol 26: 2955-2964.

Simonet WS, Lacey DL, Dunstan CR, Kelley M, Chang MS, Luthy R, Nguyen HQ, Wooden S, Bennett L, Boone T, Shimamoto G, DeRose M, Elliott
R, Colombero A, Tan HL, Trail G, Sullivan J, Davy E, Bucay N, Renshaw-Gegg L, Hughes TM, Hill D, Pattison W, Campbell P, Sander S, Van G, Tarpley J, Derby P, Lee R, Boyle WJ (1997) Osteoprotegerin: a novel secreted protein involved in the regulation of bone density. Cell 89: 309-319.

Teitelbaum SL (2007) Osteoclasts: what do they do and how do they do it? Am J Pathol 170: 427-435.

Teófilo JM, Brentegani LG, Carvalho TL (2001) A histometric study in rats of the effect of the calcium antagonist amlodipine on bone healing after tooth extraction. Arch Oral Biol 46: 375-379.

Ushijima K, Liu Y, Maekawa T, Ishikawa E, Motosugi Y, Ando H, Tsuruoka S, Fujimura A (2010) Protective effect of amlodipine against osteoporosis in stroke-prone spontaneously hypertensive rats. Eur J Pharmacol 635: 227-230.

Yu YY, Lieu S, Hu D, Miclau T, Colnot C (2012) Site specific effects of zoledronic acid during tibial and mandibular fracture repair. PLoS One 7: e31771. DOI: 10.1371/journal.pone.0031771.

Zivna H, Gradosova I, Zivny P, Cermakova E, Palicka V (2018) Effects of amlodipine on bone metabolism in orchidectomised spontaneously hypertensive rats. Pharmacology 102: 67-73.

\section{Discussion with Reviewer}

Reviewer: Do you think there could be a clinical role for amlodipine to accelerate fracture healing? If so, how would you undertake the clinical translation?

Authors: The results of the present study indicated that amlodipine had positive effects on the healing of long tubular bones, in contrast to its negative effects on alveolar and mandibular bone healing as reported in previous preclinical studies (Teófilo et al., 2001; Moraes et al., 2011). As a result, amlodipine does not have to be discontinued after fractures of long tubular bones. Moreover, we believe that a clinical trial would be appropriate given the promising results found in the present study. A retrospective analysis could be performed comparing the outcome of similar fracture types in patients with hypertension and treatment with CCBs and other hypertensive medications. If these results would show positive effects, a second prospective clinical trial could be performed in patients with hypertension and long tubular bone fractures, evaluating CCBs as potential pro-osteogenic substance.

Editor's note: The Scientific Editor responsible for this paper was Chris Evans. 